\title{
Hyperhomocysteinaemia in Sri Lankan patients with coronary artery disease
}

\author{
Sriyantha Mendis ${ }^{1}$, Pramod Ranatunga², Mohan Jayatilake ${ }^{3}$, Sanjeewa Wanninayake ${ }^{4}$ and Rajitha Wickremasinghe $^{5}$ \\ (Index words: Coronary artery disease, ischaemic heart disease)
}

\begin{abstract}
Objective To determine the association between hyperhomocysteinaemia and coronary artery disease (CAD) in a sample of Sri Lankans.

Design A case control study.

Setting Asiri Hospital, Kirula Road, Colombo 5, Sri Lanka.

Subjects 105 patients with coronary artery disease and 112 controls.

Method Fasting serum homocysteine levels were measured in 105 patients diagnosed as having CAD and in 112 unmatched controls. All patients admitted with clinical, electrocardiographical, biochemical or echocardiographical evidence of CAD were included in the study. Controls were selected from subjects admitted for health screening.

Results 105 patients with CAD and 112 controls (unmatched for age and sex) were studied. A serum homocysteine level in excess of $18.2 \mu \mathrm{mol} / \mathrm{l}$ was considered high. Confounding effects of other conventional risk factors for $\mathrm{CAD}$ were controlled using multivariate logical regression analysis.

Conclusion Hyperhomocysteinaemia is significantly associated with CAD. Multivariate logistic regression analysis indicated that the association between hyperhomocysteinaemia and CAD was confounded by other risk factors. However, statistical analysis revealed a significant independent association between hyperhomocysteinaemia and CAD (adjusted odds ratio $=2.881$ ).
\end{abstract}

\section{Introduction}

Hyperhomocysteinaemia is an independent risk factor for CAD $(1,2)$. It predisposes to premature athero-thrombotic occlusion $(3,4)$ of coronary as well as other vessels (5-8).

Homocysteine is a metabolic intermediary with a highly reactive thiol or sulfhydril moiety responsible for pathogenesis. It is formed during the metabolism of methionine, a sulphur containing essential amino acid in the diet (9). Once formed homocysteine is either transsulfurated by cystathionine- $\beta$-synthase or remethylated by methylene tetrahydrofolate reductase (10). Cystathionine- $\beta$-synthase is deficient totally in homocysteinuria and partially in its carrier state, leading to high levels of homocyteine (11). Methylene tetrahydrofolate reductase requires vitamins B6, B12 and folate as co-factors (10). Dietary deficiency of these vitamins $(12,13)$ or high methionine content of the western diet $(14,15)$ causes moderate hyperhomocysteinaemia.

High levels of homocysteine are also associated with most conventional risk factors of CAD, namely advancing age, male sex, body weight, physical inactivity, smoking, hypertension, diabetes mellitus, hypercholesterolaemia, and chronic renal failure (13).

Various mechanisms have been postulated to explain the morbidity of hyperhomocysteinaemia, namely atherosclerosis $(16,17)$, endothelial dysfunction $(18,19)$ and thrombosis $(16,20)$. Pathological effects identical to those seen in man have been reproduced in animal models (16).

Vitamin supplementation has been reported to reduce (21) or even normalise (22) serum homocysteine levels and to prevent atherosclerosis (21) and thrombotic events (16).

A study done in a semi-urban population in Sri Lanka (23) has shown a 3-fold increased risk for CAD in those with hyperhomocysteinaemia. However, a South Indian study (24) failed to show any association between hyperhomocysteinaemia and CAD. The aim of the present study was to ascertain whether hyperhomocysteinaemia is associated with CAD in the sample studied.

\section{Method}

105 patients and 112 controls were studied. The patients were consecutive patients admitted to Asiri Hospital, Colombo 5, between April 2001 and March 2002 with CAD characterised by an acute coronary syndrome (stable angina, unstable angina or myocardial infarction) or those with a documented past history of such a condition. 112 consecutive subjects admitted for routine health screening during the same period were recruited as controls.

The diagnosis of an acute coronary syndrome was made on the presence of one or more of the following documented findings: clinical: presence of highly suggestive symptoms, being on treatment that relieves relevant symptoms ie. chest pain on exertion or at rest; electrocardiographical: highly suggestive changes of cardiac ischaemia on an ECG taken at rest or during treadmill exercise;

${ }^{1}$ Physician, ${ }^{2}$ Cardiologist and ${ }^{4}$ Medical Officer, Asiri Hospital, Colombo 5; ${ }^{3}$ Cardiologist, Asha Central Hospital, Colombo 7; and ${ }^{5}$ Senior Lecturer, Department of Community Medicine and Family Medicine, Faculty of Medical Sciences, University of Sri Jayewardenapura, Nugegoda (Received 3 August, accepted 9 September 2002. Correspondence SM, Telephone +94 1 500608-9, Fax+941 508768, email: sriy@dynaweb.lk). 
biochemical: cardiac troponin $\mathrm{T}$ or I positivity, cardiac enzymes creatinine phosphokinase and CPK-MB fraction elevated to the suggestive range; echocardiographical: presence of a fresh infarct or a scar of an old infarct in the myocardium; or angiographical: critical occlusion of one or more coronary arteries. Cases with chronic renal failure and controls with evidence of chronic renal failure, cerebrovascular accidents, peripheral vascular disease or a past history of deep vein thrombosis were excluded. Informed consent was obtained from all subjects recruited into the study.

$10 \mathrm{ml}$ of venous blood was obtained from all subjects after 14 hours of fasting. Serum homocysteine levels were measured by fluorescence polarisation immunoassay using FDA-approved test kits. Fasting blood glucose levels and lipid profiles were also measured. A serum homocysteine level in excess of $18.2 \mu \mathrm{mol} / 1 \quad\left(90^{\text {th }}\right.$ percentile of the controls) was considered as high $(8,14)$. All subjects who had a fasting blood glucose level above $7 \mathrm{mmol} / \mathrm{l}(110 \mathrm{mg} / \mathrm{dl})$ were diagnosed as having diabetes; those with a resting blood pressure above 160/90 $\mathrm{mmHg}$ were diagnosed as having hypertension. Subjects with a documented history of diabetes or hypertension currently on treatment were also classified as diabetics or hypertensives.
The association between hyperhomocysteinaemia and CAD was investigated using Chi square test. A logistic regression model was used to control confounding factors. Analysis was done using SPSS.

\section{Results}

The 105 cases and 112 controls had a mean age of 58.6 years (SD 11.4) and 52.2 (SD 10.7) respectively. Of the 105 cases 64 were males and of the 112 controls 80 were males (Table 1). The controls were younger, had a lesser prevalence of diabetes, hypertension and cerebrovascular disease as compared to the cases (Table 1).

In univariate analysis there was no association between serum homocysteine levels and $\operatorname{CAD}\left(\chi^{2}=2.461\right)$ (Table 2). In a multivariate analysis using a logistic regression model hyperhomocysteinaemia was a significant predictor of CAD after controlling for age, sex and presence or absence of diabetes mellitus (adjusted odds ratio 2.881 $(95 \%$ confidence interval $=1.138-7.294)($ Table 3$)$. In the multivariate model considered, age and presence of diabetes, but not sex, were significant predictors of CAD. The presence of hyperhomocysteinaemia increases the risk of CAD about 3-fold.

Table 1. Characteristics of the population

Variable

$N$

Sex

\section{Male}

Female

63

42

Age (years)

$30-49$

50-59

60-69

$\geq 70$

Hypertension*

Yes

No

59

45

Diabetes*

Yes

No

53

51

Cerebrovascular disease

$$
\text { Yes }
$$

No

\footnotetext{
* There were no data for 4 persons
}

Cases

$\%$

60.0

40.0

25.7

27.6

27.6

19.0

56.7

43.3

51.0

49.0

15.2

84.8
Controls

N $\%$

80

71.4

28.6

47.3

26.8

21.4

4.5

5

37.6

$68 \quad 62.4$

$31 \quad 28.4$

$78 \quad 71.6$ 
Table 2. Association between serum homocysteine levels and coronary artery disease

$\begin{array}{lccc} & \begin{array}{c}\text { Cases } \\ \text { Nerum homocysteine level }\end{array} & \text { Controls } & \text { Odds ratio } \\ & N \% & N \% & \\ \text { Normal } & & & \\ (\geq 18.2 \mu \mathrm{mol} / \mathrm{l}) & 88(84) & 108(91) & (0.897 \\ \text { High } & & & \\ (>18.2 \mu \mathrm{mol} / \mathrm{l}) & 17(16) & 11(09)\end{array}$

Table 3. Results of logistic regression analysis

$\begin{array}{lccc}\text { Variable } & \begin{array}{l}\text { Regression } \\ \text { coefficient }\end{array} & \text { p-value } & \begin{array}{l}\text { Odds ratio } \\ \text { (95\% confidence interval) }\end{array} \\ \text { Constant } & -3.014 & 0.001 & \\ \text { Hyperhomocysteinaemia }^{\alpha} & 1.058 & 0.026 & 2.881(1.138-7.294) \\ \text { Age } & 0.051 & 0.001 & 1.053(1.023)=1.084) \\ \text { Diabetes mellitus } & 0.819 & 0.009 & 2.269(1.223-4.210) \\ \text { Sex }^{\gamma} & -0.472 & 0.161 & 0.624(0.322-1.207)\end{array}$

${ }^{\alpha}$ Reference group is homocysteinaemia $<18.2 \mu \mathrm{mol} / \mathrm{l}$

${ }^{\delta}$ Reference group is no diabetes mellitus

${ }^{\gamma}$ Reference group is female

\section{Discussion}

The results of this study show a 3 -fold increase in the risk of CAD among persons with hyperhomocysteinaemia as compared to persons with normal levels after controlling for other potential risk factors such as sex, age and presence of diabetes mellitus. The results of this study are similar to the earlier study done in Sri Lanka in a semiurban population (23). In the past conflicting results have been reported regarding the association between hyperhomocysteinaemia and CAD. This is probably due to the studies being done in different populations which have diverse ethnic or genetic backgrounds $(23,24,25)$, differences in prevalence of other risk factors such as coexistent diabetes (13) or differences in dietary habits (14). Inconclusive results may have also been due to differences in case definitions and inadequate sample sizes.

Mild hyperhomocysteinaemia is associated with atherothrombotic disorders, such as coronary $(1,2,23,24)$, cerebral (5), retinal (6) and peripheral vascular disease (7) and venous thrombosis (8). It has been suggested that

some conventional risk factors of CAD operate by converting homocysteine into a more reactive form (4) and also that actions of homocysteine explain many key pathological changes of atherosclerosis (3). Homocysteine has been implicated in the pathogenesis of vascular disease (21).

Standard management of hyperhomocysteinaemia includes therapy with vitamins B6, B12 and folic acid $(13,21,22)$, a cheap and acceptable intervention. Identification and treatment of high risk subjects with hyperhomocysteinaemia may reduce the incidence of CAD in Sri Lankans. A long term study with a larger number of patients and controls is necessary to confirm the results of this study. Although $18.2 \mu \mathrm{mol} / \mathrm{l}$ is taken as the upper limit of normal serum homocysteine level patients with a lower level of homocysteine may need treatment in the clinical setting. If this intervention can significantly reduce the incidence of CAD, assessment of serum homocysteine levels at regular intervals may be considered routine in the future. 


\section{References}

1. Clarke R, Daly L, Robinson K, Naughten E, Cahalane S. Fowler $\mathrm{B}$, et al. Hyperhomocysteinemia. an independent risk factor for vascular disease. The New England Journal of Medicine 1991; 323: 1149-54.

2. Murphy-Chutorian D, Alderman EL. The case that hyperhomocysteinemia is a risk factor for coronary artery disease. The American Journal of Cardiology 1994; 73: 705-6.

3. Ubbink JB. Homocysteine - an atherogenic and a thrombogenic factor? Nutrition Review 1995; 53: 325-5.

4. Fermo I, Vigano D'Angelo S, Paroni R, Mazzola G, Calori G, D'Angelo A. Prevalence of moderate hyperhomocysteinemia. in patients with early onset venous and arterial occlusive disease. Annals of Internal Medicine 1995; 123: 747-53.

5. Reis RP, Azinheira J, Reis HP, Pereira M, Baptista A, Crespo $\mathrm{M}$, et al. Homocysteine as a risk factor in early cerebrovascular disease. Acta Medica Portuguesa 1994; 7: 285-9.

6. Wenzler EM, Rademakers AJ, Boers GH, Cruysberg, JR, Webers CA, Deutman AF. Hyperhomocysteinemia in retinal artery and retinal vein occlusion. American Journal of Ophthalmology 1993; 115: 162-7.

7. Cacoub P, Godeau P. Risk factors for atherosclerotic aortoiliac occlusive disease. Annals of Vascular Surgery 1993; 7: 394-405.

8. den Heijer M, Blom HJ, Gerrits WBJ, Rosendaal FR, Haak HL, Wijermans PW, et al. Is hyperhomocysteinemia is a risk factor for recurrent venous thrombosis? Lancet 1995; 345: 882-5.

9. Findlay JBC, Hassall H, Hullin RP, Kenny AJ. Amino acids containing sulphur. In: Campbell PN, Kilby AJ (eds). Basic biochemistry for medical students. London: Academic Press, 1975: 257-61.

10. Brenton DP. Disorders of sulphur amino acid metabolism. In: Weatherall DJ. Ledingham JGG, Warrell D (eds). Oxford textbook of medicine ii. v. 3. Oxford: Oxford University Press, 1996: $1365-8$.

11. Wilken DE, Reddy SG, Guptha VJ. Homocysteinemia, ischaemic heart disease and the carrier state for homocysteinuria. Metabolism 1993; 32: 363-70.

12. Ubbink JB. Vitamin nutrition status and homocysteine: an atherogenic risk factor. Nutrition Review 1994; 52: 383-7.

13. Boushey CJ, Beresford AA, Omenn GS, Motulsky AG. A quantitative assessment of plasma homocysteine as a risk factor for vascular disease; probable benefits of increasing folic acid intake. Journal of American Medical Association 1995; 274: 1049-58.
14. Murphy-Chutorian DR, Wexman MP, Grieco AJ, Heininger JA, Glassman E, Gaull GE, et al. Methionine intolerance: a possible risk factor for coronary artery disease. Journal of American College of Cardiology 1985; 6: 725-30.

15. Bostom AG, Jacques PF, Nadeau MR, Williams RR, Ellison RC, Selhub J. Post-methionine load hyperhomocysteinemia in persons with normal fasting total plasma homocysteine: initial results from the NHLBI Family Heart Study. Atherosclerosis 1995; 116: 147-51.

16. McCully KS, Wilson RB. Homocysteine theory of atherosclerosis. Atherosclerosis 1975; 22: 215-27.

17. McCully KS. Clinical pathology of homocysteine in atherogenesis. Annals of Clinical Laboratory Science 1993; 23: 47793.

18. Hofmann MA, Kohl B, Zumbach MS. Borcea V, Bierhaus A, Henkels M, Amiral J, et al. Hyperhomocysteinemia and endothelial dysfunction in IDDM. Diabetes Care 1997; 20: 1880-6.

19. Stamler JS. Loscalzo J. Endothelium derived relaxing factor modulates the atherothrombogenic effects of homocysteine. Journal of Cardiovascular Pharmacology 1992; 20: S202-4.

20. Harker LA. Slichter SJ, Scott CR, Ross R. Vascular injury and arterial thrombosis. New England Journal of Medicine 1974; 291: $537-43$.

21. Homocysteine Lowering Trialists Collaboration. Lowering blood homocysteine with folic acid based supplements: meta-analysis of randomized trials. British Medical Journal 1998; 316: 894-8.

22. van-den-Berg M, Franken DG, Boers GH, Blon HJ, Jakobs C, Stehouwer CD, et al. Combined vitamin B6 plus folic acid therapy in young patients with atherosclerosis and hyperhomocysteinemia. Journal of Vascular Surgery 1994: 20: 933-40.

23. Mendis S, Athauda SB, Takashi K. Association between hyperhomocysteinemia and ischemic heart disease. International Journal of Cardiology 1997: 62: 221-5.

24. Chambers JC, Obeid OA, Refsum H, Ueland P, Hackett D, Hooper $\mathrm{J}$, et al. Plasma homocysteine concentrations and risk of coronary heart disease in UK Indian Asian and European men. Lancet 2000; 355: 523-7.

25. Deepa R, Velmurugan K, Saravana G, Karkuzhali K, Dwarakanath $\mathrm{V}$, Mohan V. Absence of association between serum homocysteine levels and coronary artery disease in South Indian males. Indian Heart Journal 2001; 53: 44-7. 